\title{
PROJETO INTERDISCIPLINAR DE UMA HORTA ESCOLAR NO PROCESSO DE TRANSFORMAÇÃO EM ESCOLAS SUSTENTÁVEIS
}

\section{Dalila Araújo de SANTANA ${ }^{\mathbf{1}}$; Gustavo Ferreira da Costa LIMA²; Gil Dutra FURTADO}

\begin{abstract}
${ }^{1}$ Mestra em Desenvolvimento e Meio Ambiente (PRODEMA)/Universidade Federal da Paraíba (UFPB), Brasil. E-mail: dalila.tdcb@gmail.com

${ }^{2}$ Doutor em Ciências Sociais/Universidade Estadual de Campinas (UNICAMP); Docente do Departamento de Ciências Sociais/UFPB e do Programa de Pós-Graduação em Desenvolvimento e Meio Ambiente (PRODEMA)/UFPB, Brasil. E-mail: gust3lima@uol.com.br

${ }^{3}$ Graduando em Medicina Veterinária/Centro Universitário Maurício de Nassau, João Pessoa (UNINASSAU); Engenheiro Agrônomo/Universidade Federal da Paraíba (UFPB); Doutor em Psicobiologia/Universidade Federal do Rio Grande do Norte (UFRN); Agrônomo-Sócio da Cooperativa de Agronegócio (COOPAGRO), Brasil. Email: gdfurtado@hotmail.com
\end{abstract}

Os recursos naturais são destruídos de forma rápida e isso ameaça gravemente a sobrevivência na Terra devido aos altos índices de poluição ambiental, da degradação dos ecossistemas e principalmente do consumo exagerado. A escola, que é o local de formação do cidadão, pode contribuir de forma significativa no processo de sensibilização para a prática de uma educação ambiental interdisciplinar. Essa contribuição pode acontecer através do que se aprende no seu cotidiano e de práticas pedagógicas voltadas para essa problemática. Esse trabalho foi realizado no Centro Educacional Dom Helder Câmara, uma escola do municipio de Guarabira e teve como objetivo verificar a implantação de uma horta escolar e avaliar seu potencial de sensibilização ambiental nas diversas dimensões da escola. Metodologicamente a pesquisa se valeu de uma abordagem qualitativa com uso complementar de dados quantitativos. Para tanto usou como instrumentos as entrevistas semiestruturadas e questionários com os agentes que compõem a escola, a revisão bibliográfica da literatura e a pesquisa documental dos documentos escolares, além da observação participante do desenvolvimento de todo o processo. Em relação aos resultados, foi possível constatar, que o projeto interdisciplinar da horta escolar, conseguiu sensibilizar a comunidade escolar no que diz respeito as práticas voltadas para a educação ambiental. Ações pedagógicas e interdisciplinares contribuíram de forma valiosa para este processo, uma vez que despertaram a necessidade de um trabalho contínuo de todos na escola, incluindo desde o aluno a todos os que fazem parte da comunidade escolar em todos os dias de suas atividades escolares.

Palavras-chave: Meio ambiente; Interdisciplinaridade; Horta Escolar; Instrumento; Sensibilização. 